\title{
Gene expression of membrane transporters: Importance for prognosis and progression of ovarian carcinoma
}

\author{
KATERINA ELSNEROVA $^{1-3}$, BEATRICE MOHELNIKOVA-DUCHONOVA ${ }^{1,4}$, ELA CEROVSKA $^{1,5}$, \\ MARIE EHRLICHOVA ${ }^{1,3}$, IVAN GUT ${ }^{1}$, LUKAS ROB $^{6}$, PETR SKAPA $^{7}$, MARTIN HRUDA $^{6}$, \\ ALENA BARTAKOVA $^{8}$, JIRI BOUDA ${ }^{8}$, PAVEL VODICKA $^{3,9}$, \\ PAVEL SOUCEK ${ }^{1,3}$ and RADKA VACLAVIKOVA ${ }^{1}$
}

\begin{abstract}
${ }^{1}$ Toxicogenomics Unit, National Institute of Public Health, Prague; ${ }^{2}$ Third Faculty of Medicine, Charles University in Prague, Prague; ${ }^{3}$ Biomedical Center, Faculty of Medicine in Pilsen, Charles University in Prague, Pilsen; ${ }^{4}$ Department of Oncology, Palacky University Medical School and University Hospital, Olomouc; ${ }^{5}$ Faculty of Science, Charles University in Prague, Prague; ${ }^{6}$ Department of Gynecology and Obstetrics, and ${ }^{7}$ Department of Pathology and Molecular Medicine, Second Faculty of Medicine and Motol University Hospital, Charles University in Prague, Prague;

${ }^{8}$ Department of Gynecology and Obstetrics, Faculty of Medicine and University Hospital in Pilsen, Charles University in Prague, Pilsen; ${ }^{9}$ Department of the Molecular Biology of Cancer, Institute of Experimental Medicine, Academy of Science, Prague, Czech Republic
\end{abstract}

Received October 29, 2015; Accepted December 29, 2015

DOI: $10.3892 /$ or.2016.4599

\begin{abstract}
Membrane transporters (such as ABCs, SLCs and ATPases) act in carcinogenesis and chemoresistance development, but their relevance for prognosis of epithelial ovarian cancer (EOC) remains poorly understood. We evaluated the gene expression profile of $39 \mathrm{ABC}$ and 12 SLC transporters and three ATPases in EOC tissues and addressed their putative role in prognosis and clinical course of EOC patients. Relative gene expression in a set of primary EOC $(n=57)$ and in control ovarian tissues $(n=14)$ was estimated and compared with clinical data and survival of patients. Obtained data were validated in an independent set of patients $(n=60)$. Six ABCs and SLC22A18 gene were significantly overexpressed in carcinomas when compared with controls, while expression of 12 ABCs, five SLCs, ATP7A and ATP11B was decreased. Expression of ABCA12, ABCC3, ABCC6, ABCD3, ABCG1 and SLC22A5 was higher in high grade serous carcinoma compared with other subtypes. ABCA2 gene expression significantly associated with EOC grade in both sets of patients. Notably, expression level of ABCA9,
\end{abstract}

Correspondence to: Dr Katerina Elsnerova, Toxicogenomics Unit, National Institute of Public Health, Srobarova 48, 10042 Prague 10, Czech Republic

E-mail: katerina.elsnerova@szu.cz

Dr Pavel Vodicka, Department of the Molecular Biology of Cancer, Institute of Experimental Medicine, Academy of Science, Videnska 1083, 14220 Prague 4, Czech Republic

E-mail: pvodicka@biomed.cas.cz

Key words: epithelial ovarian cancer, ABC transporters, SLC transporters, gene expression, prognosis
ABCA10, ABCC9 and SLC16A14 significantly associated with progression-free survival (PFS) of the disease in either pilot or validation sets. ABCG2 level associated with PFS in the pooled set of patients. In conclusion, ABCA2, ABCA9, ABCA10, ABCC9, ABCG2 and SLC16A14 present novel putative markers of EOC progression and together with the revealed relationship between $\mathrm{ABCA} 12, \mathrm{ABCC} 3, \mathrm{ABCC} 6$, ABCD3, ABCG1 and SLC22A5 expression, and high grade serous type of EOC should be further examined by larger follow-up study.

\section{Introduction}

Epithelial ovarian cancer (EOC) has the highest mortality rate among gynecological malignancies. Worldwide annual incidence is 6.3 new cases $/ 100,000$ women and EOC accounts for $3.7 \%$ of all female cancers $(1,2)$.

Due to lack of specific diagnostic method, EOC is usually diagnosed at advanced stages. The standard management of EOC includes cytoreductive surgery, followed by platinum- (carboplatin or cisplatin) and taxane-based chemotherapy $(3,4)$. Despite achievement of complete or partial remission after first-line chemotherapy, majority of women with advanced EOC experience disease recurrence, which suggests development of multidrug resistance (MDR) phenotype during further therapy. The development of either de novo drug resistance or induced resistance significantly influences the efficacy of systemic chemotherapy (5). Therefore, information concerning the molecular mechanisms of chemotherapy resistance and consequent validation of predictive and prognostic biomarkers is needed for optimization of treatment the algorithms in EOC.

Several membrane transporters, such as ATP-binding cassette (ABC) transporters, solute carrier (SLC) transporters 
and P-type ATPases, seem to be such potential promising biomarkers. Members of ABC protein family and ATPases are important efflux transporters, while members of SLC family act as up-take transporters. ABC transporters play an important role in cellular resistance to multiple drugs in different types of tumors, e.g. in breast (6), colorectal (7) and pancreatic cancer (8), as well as in EOC. Expression of ABCB1 has been associated with drug resistance to paclitaxel in ovarian cancer cell lines (9) and ABCC2 was associated with resistance to cisplatin in vitro (10). In addition, epigenetic reactivation of ABCG2 gene expression in ovarian cancer cells was shown to be an early molecular event leading to resistance (11). In EOC tissues, ABCC1 transcript level (as well as ABCC2 and ABCC3) was significantly increased when compared to cystadenomas and normal ovarian tissues $(12,13)$. P-glycoprotein (encoded by ABCB1 gene) was shown to associate with disease progression (14) and prognosis of ovarian cancer patients (13). ABCC1 protein expression associated with tumor grade in EOC and $\mathrm{ABCC} 4$ protein displayed an unfavorable impact on disease relapse (15). Recently, high gene expression of some members of ABCA subfamily of transporters was associated with poor outcome in ovarian high grade serous carcinoma (16).

Contrary to $\mathrm{ABC}$ transporters, information on the clinical impact of SLC membrane transporters in ovarian carcinoma patients is very limited. At present, only two studies of SLC expression levels in different EOC drug-resistant sublines were conducted providing heterogeneous results $(17,18)$. Complex analysis of SLC gene expression profile in ovarian carcinoma patients is thus needed.

Additionally, P-type ATPases were also connected to drug resistance in ovarian cancer cells. ATP7A and ATP7B transporters were shown to mediate resistance to platinum-based anticancer drugs in ovarian cancer $(19,20)$. ATP11B gene expression correlated with cisplatin resistance in human ovarian cancer cell lines and in vitro. Moreover, ATP11B gene silencing restored the sensitivity of ovarian cancer cells to cisplatin (21) suggesting the potential of its manipulation as a novel therapeutic tool. ATP11B expression also correlated with higher tumor grade in ovarian cancer tissues (21). Thus, characterization of the role of P-type ATPase membrane proteins seems highly relevant, as development of resistance is the major limitation of therapeutic efficacy of platinum compounds in ovarian cancer.

Since the role of membrane transporters in EOC still remains poorly understood, the aim of the present study was to provide gene expression profile of efflux (ABCs and ATPases) and up-take (SLCs) membrane transporters in EOC, and to identify novel putative prognostic markers of EOC progression. Gene expression profile of ABC, SLC and ATPase transporters in primary EOC tissues and in controls was assessed, and associations of expression levels with clinicopathologic data of patients were evaluated. Results of the present study provide novel targets for development of new therapies for follow-up study.

\section{Patients and methods}

Patients. The present study consists of a pilot and validation study. In the pilot study, tissue samples were obtained from
60 patients diagnosed with EOC at Motol University Hospital (Prague, Czech Republic) and at Pilsen University Hospital (Pilsen, Czech Republic) during 2009-2013. For the validation study, 57 tissue samples of EOC diagnosed at Motol University Hospital during 2011-2013 were used. Fourteen samples of ovarian tissues without morphological signs of carcinoma were used as controls in both pilot and validation studies. Control samples were obtained from patients who underwent surgery for other reason than ovarian malignancy in Motol University Hospital.

The tissue samples collected during surgery were histopathologically examined according to standard diagnostic procedures. For Ki67 immunostaining, tissue sections of 4- $\mu \mathrm{m}$ thickness were deparaffinized and rehydrated through decreasing concentrations of ethanol to water. Heat-induced epitope retrieval was performed in $0.01 \mathrm{M}$ citrate buffer (pH 6.0) at $98^{\circ} \mathrm{C}$ for $30 \mathrm{~min}$. The endogenous peroxidase activity was blocked by standard techniques at $20^{\circ} \mathrm{C}$ and tissue sections were incubated overnight at $4^{\circ} \mathrm{C}$ with primary monoclonal mouse anti-human antibody Ki67 (diluted 1:150; clone MIB-1; DakoCytomation, Glostrup, Denmark). Immunocomplexes of the antigen and the primary antibody were visualized using N-Histofine Simple Stain MAX PO (MULTI) detection system (Nichirei Biosciences, Tokyo, Japan) with 3,3'-diaminobenzidine tetrahydrochloride (Fluka Chemie, Buchs, Switzerland) as a chromogen. All sections were stained with hematoxylin, dehydrated and mounted. Only nuclear staining, of any intensity, was considered positive. Ki67 hot-spots were identified in each tissue section under low magnification and the level of Ki67 expression was quantified in 10 different high power fields as a percentage of positive cells.

The tissue samples were fresh-frozen and stored at $-80^{\circ} \mathrm{C}$ until isolation of RNA, DNA and protein. The following data on patients were retrieved from medical records: the patients age at the time of diagnosis, FIGO stage, tumor grade and type of EOC, expression of protein marker Ki67 in percentage (available only for patients from Motol University Hospital) and progression of the disease evaluated as time to progression (TTP) in months as specified in Table I. Patients were treated after surgery by adjuvant regimens based on paclitaxel and platinum drugs. Follow-up of patients was performed by regular physical examinations and monitoring of CA-125 levels.

All patients were informed about the aims of the present study, and provided their written consent to participate in the study. The design of the study was approved by the Ethics Commission of the National Institute of Public Health (Prague, Czech Republic), Motol University Hospital and Pilsen University Hospital.

Isolation of total RNA and cDNA preparation. Tumor and control samples were ground to powder under liquid nitrogen in mortar with pestle. Total RNA, DNA and protein were isolated using AllPrep DNA/RNA/Protein Mini kit (Qiagen, Hildesheim, Germany) according to the manufacturer's protocol. Total RNA was quantified by Quant-iT RiboGreen RNA assay kit (Invitrogen, Eugene, OR, USA). cDNA was synthesized using Revert Aid First Strand cDNA Synthesis kit (MBI Fermentas, Vilnius, Lithuania) with $0.5 \mu \mathrm{g}$ of total RNA 
Table I. Clinicopathologic characteristics of EOC patients in the study.

\begin{tabular}{|c|c|c|}
\hline Characteristics & $\begin{array}{l}\text { Pilot set } \\
\mathrm{N}(\%)^{\mathrm{a}}\end{array}$ & $\begin{array}{l}\text { Validation set } \\
\mathrm{N}(\%)^{\mathrm{a}}\end{array}$ \\
\hline $\begin{array}{l}\text { Median age at diagnosis, } \\
\text { years }\end{array}$ & $62.5 \pm 11.2$ & $57.0 \pm 9.8$ \\
\hline \multicolumn{3}{|l|}{ FIGO stage } \\
\hline I & $4(7.3)$ & $3(5.4)$ \\
\hline II & $6(10.9)$ & $2(3.6)$ \\
\hline III & $41(74.5)$ & $47(83.9)$ \\
\hline IV & $4(7.3)$ & $4(7.1)$ \\
\hline Not available & 5 & 1 \\
\hline \multicolumn{3}{|l|}{ EOC type } \\
\hline Others & $10(18.2)$ & $3(5.3)$ \\
\hline HGSC & $45(81.8)$ & $54(94.7)$ \\
\hline Not available & 5 & 0 \\
\hline \multicolumn{3}{|l|}{ Histological grade } \\
\hline G1 & $5(8.5)$ & $1(1.8)$ \\
\hline G2 & $11(18.6)$ & $9(15.8)$ \\
\hline G3 & $43(72.9)$ & $47(82.5)$ \\
\hline Not available & 1 & 0 \\
\hline \multicolumn{3}{|l|}{ Distant metastases } \\
\hline Present & $4(8.0)$ & $4(7.1)$ \\
\hline Absent & $46(92.0)$ & $52(92.9)$ \\
\hline Not available & 10 & 1 \\
\hline \multicolumn{3}{|l|}{ Time to progression } \\
\hline Median \pm SD $(\%)$ & $12.5 \pm 8.7$ & $13.0 \pm 10.7$ \\
\hline Number of evaluated patients ${ }^{b}$ & 24 & 29 \\
\hline \multicolumn{3}{|l|}{ Ki67 protein expression } \\
\hline Median \pm SD $(\%)$ & $30.0 \pm 25.4$ & $25.0 \pm 19.4$ \\
\hline Number of evaluated patients ${ }^{\mathrm{c}}$ & 21 & 57 \\
\hline
\end{tabular}

${ }^{\mathrm{a} N u m b e r}$ of patients with percentage in parentheses is shown; ${ }^{\mathrm{b}}$ only patients without distant metastases who showed progression in their disease were evaluated; 'data are available only for samples from Motol University Hospital. EOC, epithelial ovarian cancer; SD, standard deviation.

as previously described (22). Quality of cDNA was confirmed by PCR amplification of ubiquitin $\mathrm{C}$ fragment (23).

In the pilot study, pre-amplified cDNA was used for all experiments. Two point five milliliters of cDNA was pre-amplified using 5.0 $\mu \mathrm{l}$ of PerfeCTa PreAmp SuperMix (Quanta BioSciences, Gaithersburg, MD, USA), $6.25 \mu$ l of pooled assay mix containing all target TaqMan Gene Expression Assays (Life Technologies, Foster City, CA, USA; listed in Table II) and nuclease-free water in a final volume of $25.0 \mu \mathrm{l}$. A total of 14 pre-amplification cycles were used according to the manufacturer's protocol. The pre-amplified cDNA was stored at $-20^{\circ} \mathrm{C}$ until real-time PCR was performed. For the validation phase of the study, cDNA without pre-amplification was used to test robustness of putative markers.
Quantitative real-time PCR. Quantitative real-time PCR (qPCR) was performed by the use of ViiA7 Real-Time PCR system (Life Technologies). In the pilot study, reaction mixture contained $2.5 \mu \mathrm{l}$ of TaqMan Gene Expression Master Mix, $0.25 \mu \mathrm{l}$ of a specific TaqMan Gene Expression Assay, $2.0 \mu 1$ of cDNA 32-times diluted in TE buffer, and nuclease-free water to make a final volume of $5.0 \mu \mathrm{l}$. Cycling parameters were, initial hold at $50^{\circ} \mathrm{C}$ for $2 \mathrm{~min}$ and denaturation at $95^{\circ} \mathrm{C}$ for $10 \mathrm{~min}$ followed by 45 cycles consisting of denaturation at $95^{\circ} \mathrm{C}$ for $15 \mathrm{sec}$ and annealing/extension at $60^{\circ} \mathrm{C}$ for $60 \mathrm{sec}$ (exceptions are highlighted in the list of TaqMan Gene Expression Assays, Table II). Fluorescence values were acquired after each extension phase. Samples were analyzed in duplicates and samples with standard deviation of duplicates $>0.5 \mathrm{Ct}$ were re-analyzed.

As a calibrator, equimolar mixture of 10 control samples was used. The calibrator was 20-times diluted in nuclease-free water. Relative standard curve was generated from 5-log dilutions of the calibrator. Reaction efficiency of all assays was $>90 \%$ (under conditions described in Table II). Non-template control containing nuclease-free water instead of cDNA was used.

In the validation study, reaction mixture contained $1.0 \mu \mathrm{l}$ of 5X Hot FIREPol Probe qPCR Mix Plus (Solis BioDyne, Tartu, Estonia), $0.25 \mu \mathrm{l}$ of a specific TaqMan Gene Expression Assay, $2.0 \mu 1$ of cDNA 8-times diluted in nuclease-free water, and nuclease-free water to make a final volume of $5.0 \mu \mathrm{l}$. qPCR conditions were used as optimized in the pilot study.

Selection of reference genes. Stability of six potential reference genes (GAPDH, GUSB, PPIA, TBP, UBC and YWHAZ) was evaluated in the pilot sample set. NormFinder and geNorm software was used for analysis of results (24).

The real-time PCR study design adhered to the Minimum Information for Publication of Quantitative Real-Time PCR Experiments Guidelines (25).

Data analysis. Relative transcript levels in tumor and control tissues samples were compared using REST 2009 software, [Qiagen; (26)].

Statistical analyses of associations between gene expression and clinicopathologic data of patients were carried out by SPSS v16.0 software (SPSS, Inc., Chicago, IL, USA). A ratio of $\mathrm{Ct}$ for a particular target gene to an arithmetic mean of all reference genes was calculated for each sample, as described in Ehrlichová et al (13). Non-parametric Kruskal-Wallis test was used for evaluation of relationships between gene expression and FIGO stage (stage I/II vs. III/IV), tumor grade (grade 1/2 vs. 3), Ki67 (cut-off 15\%) and EOC type (high grade serous EOC vs. other types). Spearman rank test was used for evaluation of correlation between mRNA level and percentage of Ki67-positive cells. Time-to-progression was defined as the time elapsed between surgical treatment and disease progression or death from any cause. Progression-free survival (PFS) was evaluated only for patients without distant metastases. Survival functions were plotted by the Kaplan-Meier method and statistical significance was evaluated by the log-rank test. For multivariate analysis the Cox proportional hazards model was used. P-values are departures from two-sided tests. A P-value of $<0.05$ was considered to indicate a statistically significant result. The issue of multiple testing was addressed by validation of results in a two-phase study. 
Table II. The TaqMan Gene Expression Assays used in the present study.

\begin{tabular}{|c|c|c|c|c|}
\hline Gene symbol & Assay ID & $\begin{array}{l}\text { Gene bank } \\
\text { accession no. }\end{array}$ & Gene name & $\begin{array}{l}\text { Amplicon } \\
\text { ength (bp) }\end{array}$ \\
\hline GAPDH & Hs02758991_g1 & NM_002046.4 & Glyceraldehyde-3-phosphate dehydrogenase & 93 \\
\hline GUSB & Hs99999900_m1 & NM_000181.3 & Glucuronidase, $\beta$ & 81 \\
\hline$P_{P P I}^{a}$ & Hs99999904_m1 & NM_021130.3 & Peptidylprolyl isomerase A & 98 \\
\hline$T B P$ & Hs00920495m1 & NM_003194.4 & TATA box binding protein & 112 \\
\hline$U B C^{a}$ & Hs00824723_m1 & NM_021009.5 & Ubiquitin $\mathrm{C}$ & 71 \\
\hline$Y W H A Z^{a}$ & Hs03044281_g1 & NM_001135700.1 & $\begin{array}{l}\text { Tyrosine } 3 \text {-monooxygenase/tryptophan } 5 \text {-monooxygenase } \\
\text { activation protein, } \zeta \text { polypeptide }\end{array}$ & 106 \\
\hline ABCA1 & Hs00194045_m1 & NM_005502.3 & ATP-binding cassette, sub-family A (ABC1), member 1 & 125 \\
\hline $\mathrm{ABCA} 2$ & Hs00242232_m1 & NM_212533.2 & ATP-binding cassette, sub-family A ( $\mathrm{ABC} 1$ ), member 2 & 58 \\
\hline $\mathrm{ABCA} 3$ & Hs00184543_m1 & NM_001089.2 & ATP-binding cassette, sub-family A ( $\mathrm{ABC} 1)$, member 3 & 77 \\
\hline ABCA7 & Hs00185303_m1 & NM_019112.3 & ATP-binding cassette, sub-family A ( $\mathrm{ABC} 1)$, member 7 & 80 \\
\hline ABCA8 & Hs00992371_m1 & NM_007168.2 & ATP-binding cassette, sub-family A ( $\mathrm{ABC} 1)$, member 8 & 85 \\
\hline ABCA9 & Hs00329320_m1 & NM_080283.3 & ATP-binding cassette, sub-family A ( $\mathrm{ABC} 1)$, member 9 & 145 \\
\hline $\mathrm{ABCA} 10^{\mathrm{b}}$ & Hs00365268_m1 & NM_080282.3 & ATP-binding cassette, sub-family A ( $\mathrm{ABC} 1)$, member 10 & 127 \\
\hline ABCA12 & Hs00292421_m1 & NR_103740.1 & ATP-binding cassette, sub-family A (ABC1), member 1 & 77 \\
\hline ABCA13 & Hs01110169_m1 & NM_152701.3 & ATP-binding cassette, sub-family A ( $\mathrm{ABC} 1)$, member 13 & 80 \\
\hline ABCB1 & Hs00184491_m1 & NM_000927.4 & ATP-binding cassette, sub-family B (MDR/TAP), member 1 & 110 \\
\hline $\mathrm{ABCB} 2$ & Hs00388677_m1 & NM_000593.5 & Transporter 1, ATP-binding cassette, sub-family B (MDR/TAP) & P) 60 \\
\hline ABCB3 & Hs00241060_m1 & NM_018833.2 & Transporter 2, ATP-binding cassette, sub-family B (MDR/TAP) & P) 66 \\
\hline ABCB4 & Hs00240956_m1 & NM_018850.2 & ATP-binding cassette, sub-family B (MDR/TAP), member 4 & 73 \\
\hline ABCB5 & Hs00698751_m1 & NM_178559.5 & ATP-binding cassette, sub-family B (MDR/TAP), member 5 & 90 \\
\hline ABCB11 & Hs00184824_m1 & NM_003742.2 & ATP-binding cassette, sub-family B (MDR/TAP), member 11 & 63 \\
\hline $\mathrm{ABCC} 1$ & Hs00219905_m1 & NM_004996.3 & ATP-binding cassette, sub-family C (CFTR/MRP), member 1 & 74 \\
\hline $\mathrm{ABCC} 2$ & Hs00166123_m1 & NM_000392.3 & ATP-binding cassette, sub-family C (CFTR/MRP), member 2 & 75 \\
\hline $\mathrm{ABCC} 3$ & Hs00358656_m1 & NM_003786.3 & ATP-binding cassette, sub-family C (CFTR/MRP), member 3 & 98 \\
\hline $\mathrm{ABCC} 4$ & Hs00195260_m1 & NM_005845.3 & ATP-binding cassette, sub-family C (CFTR/MRP), member 4 & 86 \\
\hline $\mathrm{ABCC} 5$ & Hs00981089_m1 & NM_005688.2 & ATP-binding cassette, sub-family C (CFTR/MRP), member 5 & 68 \\
\hline ABCC6 & Hs00184566_m1 & NM_001171.5 & ATP-binding cassette, sub-family C (CFTR/MRP), member 6 & 56 \\
\hline $\mathrm{ABCC} 7$ & Hs00357011_m1 & NM_000492.3 & ATP-binding cassette sub-family $\mathrm{C}$, member 7 & 93 \\
\hline $\mathrm{ABCC} 8$ & Hs00165861_m1 & NM_000352.3 & ATP-binding cassette, sub-family C (CFTR/MRP), member 8 & 137 \\
\hline $\mathrm{ABCC} 9$ & Hs00245832_m1 & NM_020297.2 & ATP-binding cassette, sub-family C (CFTR/MRP), member 9 & 70 \\
\hline $\mathrm{ABCC} 10$ & Hs00375716_m1 & NM_033450.2 & ATP-binding cassette, sub-family C (CFTR/MRP), member 10 & $0 \quad 142$ \\
\hline ABCC11 & Hs01090768_m1 & NM_032583.3 & ATP-binding cassette, sub-family C (CFTR/MRP), member 11 & 76 \\
\hline $\mathrm{ABCC} 12$ & Hs00264354_m1 & NM_033226.2 & ATP-binding cassette, sub-family C (CFTR/MRP), member 12 & 290 \\
\hline ABCD1 & Hs00163610_m1 & NM_000033.3 & ATP-binding cassette, sub-family D (ALD), member 1 & 101 \\
\hline $\mathrm{ABCD} 2$ & Hs00193054_m1 & NM_005164.3 & ATP-binding cassette, sub-family D (ALD), member 2 & 109 \\
\hline $\mathrm{ABCD} 3$ & Hs00161065_m1 & NM_002858.3 & ATP-binding cassette, sub-family D (ALD), member 3 & 91 \\
\hline $\mathrm{ABCD} 4$ & Hs00245340_m1 & NM_005050.3 & ATP-binding cassette, sub-family D (ALD), member 4 & 117 \\
\hline ABCE1 & Hs01009190_m1 & NM_001040876.1 & ATP-binding cassette, sub-family E (OABP), member 1 & 91 \\
\hline $\mathrm{ABCF} 1$ & Hs00153703_m1 & NM_001090.2 & ATP-binding cassette, sub-family F (GCN20), member 1 & 69 \\
\hline $\mathrm{ABCF} 2$ & Hs00606493_m1 & NM_005692.4 & ATP-binding cassette, sub-family F (GCN20), member2 & 113 \\
\hline $\mathrm{ABCF} 3$ & Hs00217977_m1 & NM_018358.2 & ATP-binding cassette, sub-family F (GCN20), member3 & 61 \\
\hline ABCG1 & Hs00245154_m1 & NM_207629.1 & ATP-binding cassette, sub-family G (WHITE), member 1 & 58 \\
\hline ABCG2 & Hs00184979_m1 & NM_004827.2 & ATP-binding cassette, sub-family G (WHITE), member2 & 92 \\
\hline ABCG5 & Hs00223686_m1 & NM_022436.2 & ATP-binding cassette, sub-family G (WHITE), member5 & 60 \\
\hline ABCG8 & Hs00223690_m1 & NM_022437.2 & ATP-binding cassette, sub-family G (WHITE), member 8 & 63 \\
\hline ATP7A & Hs00163707_m1 & NM_000052.6 & ATPase, $\mathrm{Cu}^{++}$transporting, $\alpha$ polypeptide & 88 \\
\hline ATP7B & Hs00163739_m1 & NM_000053.3 & ATPase, $\mathrm{Cu}^{++}$transporting, $\beta$ polypeptide & 83 \\
\hline ATP11B & Hs00966779_m1 & NM_014616.2 & ATPase, class VI, type 11B & 79 \\
\hline SLC16A14 & Hs00541300_m1 & NM_152527.4 & Solute carrier family 16 , member 14 & 106 \\
\hline SLC22A1 & Hs00427552_m1 & NM_003057.2 & Solute carrier family 22 (organic cation transporter), member 1 & 79 \\
\hline
\end{tabular}


Table II. Continued.

\begin{tabular}{lclll}
\hline Gene symbol & Assay ID & $\begin{array}{c}\text { Gene bank } \\
\text { accession no. }\end{array}$ & \multicolumn{1}{c}{ Gene name } & $\begin{array}{c}\text { Amplicon } \\
\text { length (bp) }\end{array}$ \\
\hline SLC22A2 & Hs01010723_m1 & NM_003058.3 & Solute carrier family 22 (organic cation transporter), member 2 & 120 \\
SLC22A3 & Hs01009568_m1 & NM_021977.3 & Solute carrier family 22 (organic cation transporter), member 3 & 73 \\
SLC22A4 & Hs00268200_m1 & NM_003059.2 & $\begin{array}{l}\text { Solute carrier family 22 (organic cation/zwitterion transporter), } \\
\text { member 4 }\end{array}$ & 76 \\
& & & No & 65 \\
SLC22A5 & Hs00929869_m1 & NM_003060.3 & $\begin{array}{l}\text { Solute carrier family 22 (organic cation/carnitine transporter), } \\
\text { member 5 }\end{array}$ & 65 \\
SLC22A11 & Hs00945829_m1 & NM_018484.2 & $\begin{array}{l}\text { Solute carrier family 22 (organic anion/urate transporter), } \\
\text { member 11 }\end{array}$ & 82 \\
SLC22A18 & Hs00180039_m1 & NM_002555.5 & Solute carrier family 22, member 18 & 81 \\
SLC31A1 & Hs00977268_g1 & NM_001859.3 & Solute carrier family 31 (copper transporter), member 1 & 81 \\
SLC31A2 & Hs00156984_m1 & NM_001860.2 & Solute carrier family 31 (copper transporter), member 2 & 70 \\
SLC47A1 & Hs00217320_m1 & NM_018242.2 & Solute carrier family 47 (multidrug and toxin extrusion), member 1 & 74 \\
SLC47A2 & Hs00945650_m1 & NM_152908.3 & Solute carrier family 47 (multidrug and toxin extrusion), member 2 & 86 \\
\hline
\end{tabular}

${ }^{\text {a}}$ Reference genes used for normalization of results; ${ }^{b}$ annealing temperature during real-time PCR was set to $62^{\circ} \mathrm{C}$; ${ }^{\mathrm{c}}$ annealing temperature during real-time PCR was set to $58^{\circ} \mathrm{C}$.
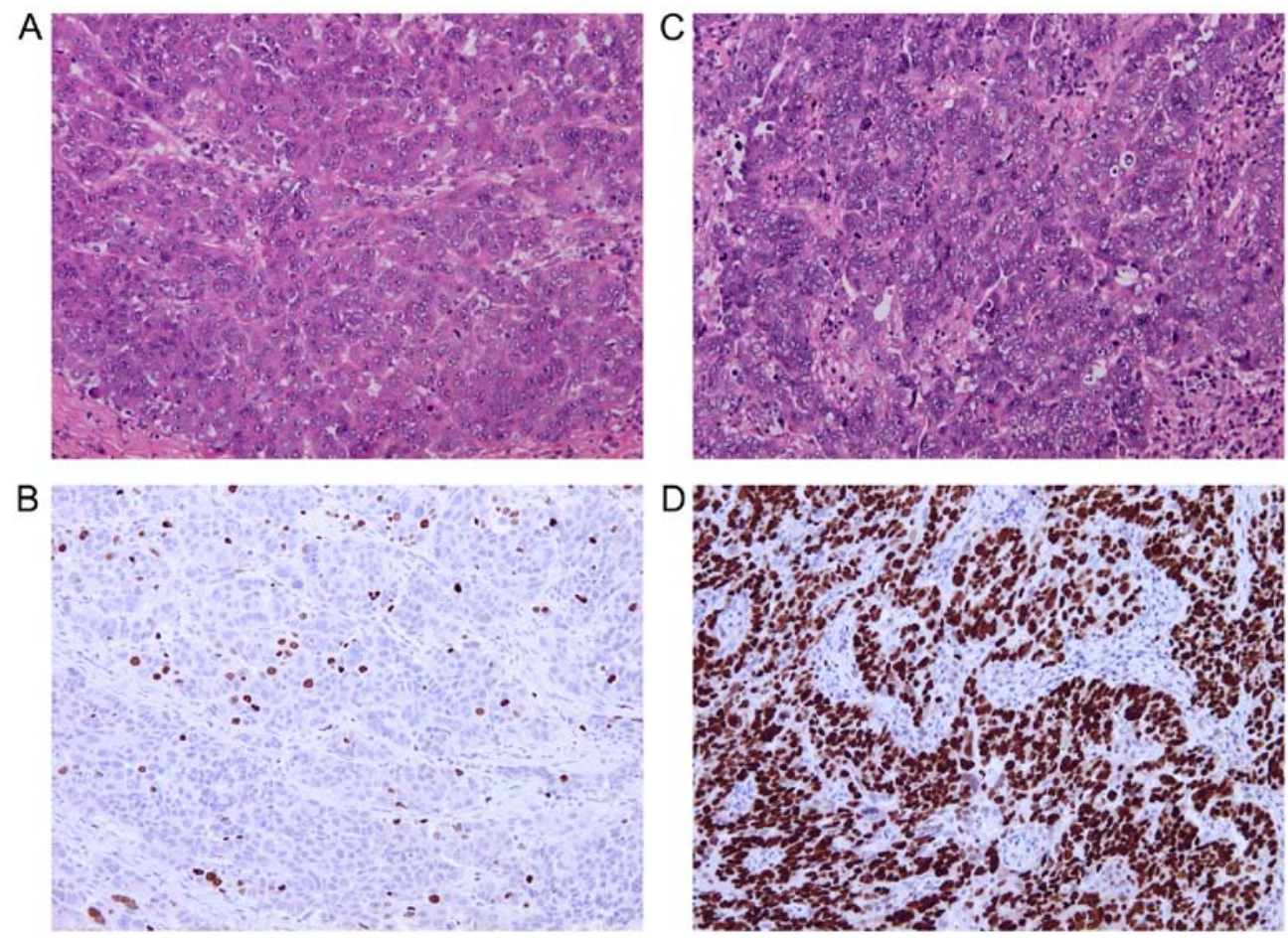

Figure 1. Variability of Ki67 immunoexpression in ovarian HGSC. Corresponding hematoxylin and eosin (H\&E) stained sections are shown. (A and B) Low expression (A, H\&E; B, Ki67 immunohistochemistry; magnification, x200). (C and D) High expression (C, H\&E; D, Ki67 immunohistochemistry; magnification, $\mathrm{x} 200)$.

\section{Results}

Characteristics of patients. Sets of 60 and 57 ovarian cancer patients were used in the pilot and validation study, respectively. Percentage of advanced stage or high grade EOC, as well as median age at diagnosis, was similar in the pilot and in the validation set of patients. The median age at diagnosis ( \pm standard deviation) was $62.5 \pm 11.2$ and $57.0 \pm 9.8$ years in the pilot and validation set of patients, respectively, and did not significantly differ from the age of controls used for comparison (53.5 \pm 13.3 years). In contrast, tissue samples significantly differed in expression level of marker Ki67 (30.0 25.4 and $25.0 \pm 19.4 \%$ in the pilot and validation set of EOC tissues, respectively), while it was $\leq 1 \%$ in the control tissues (Fig. 1).

Disease progression occurred in 24 and 29 patients in the pilot and validation sets, respectively. Median follow-up 

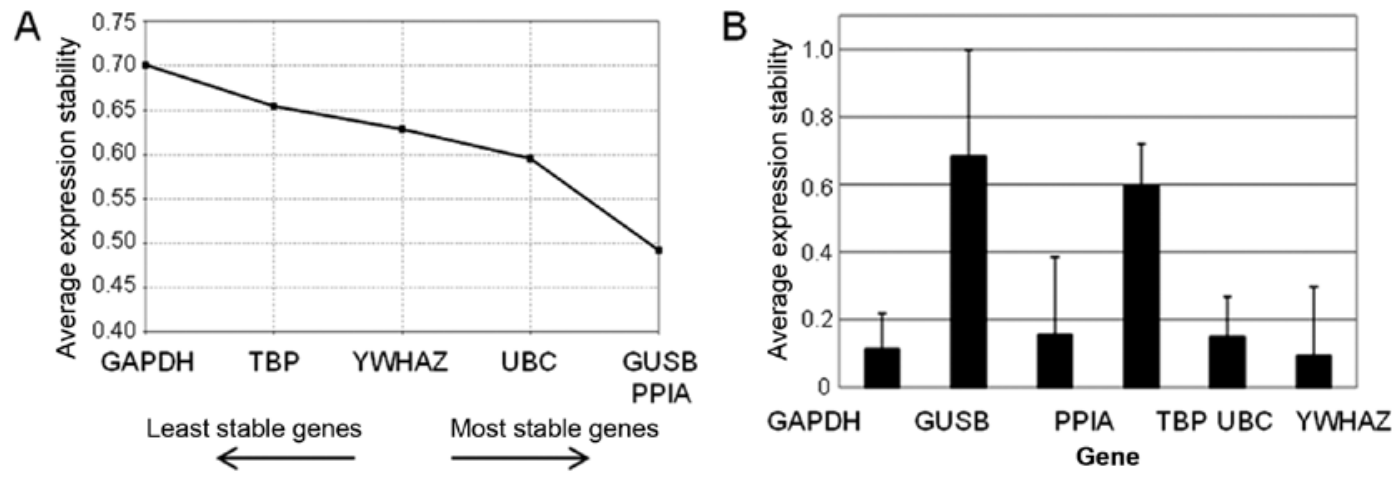

Figure 2. Stability of tested reference genes evaluated by geNorm (A) and NormFinder (B) programs. PPIA, UBC and YWHAZ genes were further used as reference genes in the present study.

( \pm standard deviation) was $12.5 \pm 8.7$ months in the pilot set of patients and $13.0 \pm 10.7$ months in the validation set. The relationship between TTP of these patients and gene expression in EOC samples (PFS) was evaluated.

Tissue samples of 14 patients without morphological signs of primary ovarian carcinoma in their ovaries (ovarian leiomyoma, $n=6$; uterine leiomyoma, $n=2$; benign ovarian cyst, $\mathrm{n}=1$; cervical carcinoma, $\mathrm{n}=2$; endometrial carcinoma, $\mathrm{n}=2$; sarcoma, $n=1$ ) were used as controls. Clinicopathological characteristics of EOC patients are described in Table I.

Selection of reference genes. Six genes were tested for stability in the pilot set of patients. PPIA, UBC and YWHAZ were consistently evaluated among the most stable four genes by both geNorm (Fig. 2A) and NormFinder (Fig. 2B) programs. Therefore, these genes were selected as reference genes for the study on ovarian tissues.

Transcript levels of transporter genes in the pilot set. Transcripts of the analyzed 39 ABCs, 12 SLCs and three ATPase genes (Table II) were analyzed by qPCR in all tumor and control samples in the pilot study. Six ABC (ABCB5, $\mathrm{ABCC} 7, \mathrm{ABCC} 8, \mathrm{ABCC} 11, \mathrm{ABCC} 12$ and $\mathrm{ABCG} 5)$ and three SLCs (SLC22A2, SLC22A11 and SLC47A2) genes were expressed below limit of detection and thus were not further evaluated. Significantly higher transcript levels of ABCA7, ABCA12, ABCA13, ABCB2, ABCB3, ABCC3 and SLC22A18 were found in EOC tumors when compared with the control ovarian tissues. In contrast, ABCA8, ABCA9, ABCA10, ABCB1, ABCB4, ABCC9, ABCD3, ABCD4, ABCE1, ABCF1, ABCF3, ABCG2, SLC16A4, SLC22A1, SLC22A3, SLC22A5, SLC47A1, ATP7A and ATP11B levels were significantly decreased in tumors, when compared with controls (Table III). The rest of the genes were not significantly deregulated in EOC tissues.

Associations between transcript levels and clinicopathological data in the pilot set. Transcript levels of target genes in EOC tissues were evaluated for their associations with clinicopathological characteristics (FIGO stage, grade, EOC type and expression of protein marker Ki67) (Table IV-A) and PFS of patients assessed as TTP (Fig. 3A).

ABCA3, ATP7A and ATP7B levels were significantly higher in advanced FIGO III/IV stage carcinomas compared with stages I or II. The opposite tendency was seen for expression of ABCA12 gene, i.e., lower levels in patients with extrapelvic metastases (FIGO III or IV). Lower ABCA2 transcript level was found in tumors with grade 3 compared to the more differentiated grade 1 or 2 tumors. ABCA12, ABCC3, ABCC6, ABCD3, ABCG1 and SLC22A5 were overexpressed in high grade serous carcinomas (HGSC) compared to other EOC subtypes. A significant negative correlation of $\mathrm{Ki} 67$ protein expression with ABCA8, ABCA9, ABCB1, ABCC3, ABCD2 and ABCG1 was also observed. Using cut-off level 15\%, correlations of Ki67 expression with ABCB1, ABCC3, ABCD2, and ABCG1 were confirmed. In addition, significant associations with ABCA10, ABCG2 and SLC16A14 were revealed. Moreover, expression of ABCC9 gene significantly associated with PFS of patients with EOC in the pilot set $(n=24)$. Patients with higher than median intratumoral ABCC9 level had significantly shorter TTP than the rest of patients [hazard ratio $(\mathrm{HR})=2.64 ; 95 \%$ confidence interval (95\% CI), 1.05-6.67). This association was significant also in the Cox regression multiparametric analysis adjusted to the stage, grade and presence of distant metastases $(\mathrm{P}=0.040)$.

Transcript levels of transporter genes in the validation set. Results of the pilot study were verified in the validation set of patients. All genes that associated with any of clinicopathological characteristics in the pilot set of patients (Table IV-A) were selected for subsequent validation.

The majority of deregulations in tumors compared to controls observed in the pilot set were confirmed in the validation study. Namely, ABCA8, ABCA9, ABCA10, ABCB1, ABCC9, ABCG2, ATP7A, SLC16A14 and SLC22A5 were downregulated in tumors compared to control tissues. ABCA12 and $\mathrm{ABCC} 3$ genes were overexpressed in tumors (Table III).

Associations between transcript levels and clinicopathological data in the validation set. Associations between gene expression levels of candidate genes and FIGO stage, grade of tumors and $\mathrm{Ki} 67$ expression were evaluated in the validation set (Table IV-B). However, low numbers of patients with other than HGSC tumor type in the validation set prevented the confirmation of these associations.

The association of ABCA2 expression in EOC with grade was confirmed. In contrast with the pilot study, analysis of the 
Table III. Differences in the relative transcript levels of target genes between controls and EOC tissues in the pilot and validation sets.

\begin{tabular}{|c|c|c|c|c|c|c|c|}
\hline \multirow[b]{2}{*}{ Gene } & \multirow[b]{2}{*}{$\begin{array}{c}\text { Reaction } \\
\text { efficiency }(\%)\end{array}$} & \multicolumn{3}{|c|}{ Pilot set } & \multicolumn{3}{|c|}{ Validation set } \\
\hline & & $\begin{array}{c}\text { Expression } \\
\text { difference }\end{array}$ & $\mathrm{P}$-value ${ }^{\mathrm{a}}$ & $\begin{array}{l}\text { EOC tissues vs. } \\
\text { controls }\end{array}$ & $\begin{array}{l}\text { Expression } \\
\text { difference }\end{array}$ & $\mathrm{P}$-value ${ }^{\mathrm{a}}$ & $\begin{array}{c}\text { EOC tissues vs } \\
\text { controls }\end{array}$ \\
\hline ABCA1 & 93 & 0.84 & 0.340 & & & & \\
\hline ABCA2 & 97 & 1.12 & 0.491 & & 1.16 & 0.424 & \\
\hline ABCA3 & 95 & 0.83 & 0.314 & & 0.99 & 0.950 & \\
\hline ABCA7 & 94 & 3.21 & $<0.001$ & Up & & & \\
\hline ABCA8 & 93 & 0.04 & $<0.001$ & Down & 0.02 & $<0.001$ & Down \\
\hline ABCA9 & 91 & 0.05 & $<0.001$ & Down & 0.03 & $<0.001$ & Down \\
\hline ABCA10 & 96 & 0.03 & $<0.001$ & Down & 0.01 & $<0.001$ & Down \\
\hline ABCA12 & 98 & 2.56 & 0.038 & Up & 2.34 & 0.019 & $\mathrm{Up}$ \\
\hline ABCA13 & 98 & 7.21 & $<0.001$ & Up & & & \\
\hline ABCB1 & 91 & 0.32 & $<0.001$ & Down & 0.33 & $<0.001$ & Down \\
\hline ABCB2 & 95 & 1.93 & 0.001 & Up & & & \\
\hline $\mathrm{ABCB} 3$ & 97 & 1.56 & 0.013 & Up & & & \\
\hline ABCB4 & 97 & 0.45 & 0.003 & Down & & & \\
\hline ABCB11 & 93 & 2.52 & 0.116 & & & & \\
\hline $\mathrm{ABCC} 1$ & 96 & 1.01 & 0.946 & & & & \\
\hline $\mathrm{ABCC} 2$ & 99 & 0.70 & $0.070 \mathrm{~S}$ & & & & \\
\hline $\mathrm{ABCC} 3$ & 94 & 4.49 & $<0.001$ & Up & 4.33 & $<0.001$ & Up \\
\hline $\mathrm{ABCC} 4$ & 94 & 1.09 & 0.643 & & & & \\
\hline ABCC5 & 97 & 1.08 & 0.587 & & & & \\
\hline ABCC6 & 99 & 0.76 & 0.312 & & 0.72 & 0.289 & \\
\hline ABCC9 & 94 & 0.18 & $<0.001$ & Down & 0.16 & $<0.001$ & Down \\
\hline ABCC10 & 93 & 1.03 & 0.807 & & & & \\
\hline $\mathrm{ABCD} 1$ & 94 & 0.91 & 0.440 & & & & \\
\hline ABCD2 & 91 & 1.07 & 0.804 & & 1.05 & 0.887 & \\
\hline $\mathrm{ABCD3}$ & 92 & 0.67 & $<0.001$ & Down & 0.86 & 0.137 & \\
\hline ABCD4 & 94 & 0.76 & 0.0240 & Down & & & \\
\hline ABCE1 & 95 & 0.59 & $<0.001$ & Down & & & \\
\hline $\mathrm{ABCF} 1$ & 97 & 0.73 & 0.001 & Down & & & \\
\hline $\mathrm{ABCF} 2$ & 92 & 0.99 & 0.957 & & & & \\
\hline $\mathrm{ABCF} 3$ & 93 & 0.69 & $<0.001$ & Down & & & \\
\hline ABCG1 & 96 & 0.91 & 0.626 & & 1.00 & 0.975 & \\
\hline ABCG2 & 94 & 0.11 & $<0.001$ & Down & 0.08 & $<0.001$ & Down \\
\hline ABCG8 & 91 & 0.74 & 0.595 & & & & \\
\hline ATP7A & 94 & 0.43 & $<0.001$ & Down & 0.43 & $<0.001$ & Down \\
\hline ATP7B & 95 & 1.08 & 0.701 & & 1.06 & 0.760 & \\
\hline АТР11B & 97 & 0.50 & $<0.001$ & Down & & & \\
\hline SLC16A14 & 92 & 0.17 & $<0.001$ & Down & 0.10 & $<0.001$ & Down \\
\hline SLC22A1 & 99 & 0.56 & 0.007 & Down & & & \\
\hline SLC22A3 & 96 & 0.09 & $<0.001$ & Down & & & \\
\hline SLC22A4 & 98 & 0.89 & 0.612 & & & & \\
\hline SLC22A5 & 95 & 0.55 & $<0.001$ & Down & 0.45 & $<0.001$ & Down \\
\hline SLC22A18 & 94 & 1.76 & 0.002 & Up & & & \\
\hline SLC31A1 & 93 & 1.12 & 0.309 & & & & \\
\hline SLC31A2 & 96 & 0.97 & 0.873 & & & & \\
\hline SLC47A1 & 94 & 0.16 & $<0.001$ & Down & & & \\
\hline
\end{tabular}


Table IV. Associations between transcript levels of the investigated genes in EOC tissues and clinicopathologic data of patients that were revealed in the pilot study $\mathrm{A}$, and in the validation study B.

A, Pilot set

\begin{tabular}{|c|c|c|c|c|c|c|c|}
\hline \multirow[b]{3}{*}{ Gene } & \multirow[b]{2}{*}{ FIGO stage } & \multirow[b]{2}{*}{ Grade } & \multirow{2}{*}{\multicolumn{2}{|c|}{ EOC type }} & \multicolumn{3}{|c|}{ Ki67 protein expression ${ }^{\mathrm{d}}$} \\
\hline & & & & & \multicolumn{2}{|c|}{ Cut-off $15 \%$} & \multirow[b]{2}{*}{$\%$} \\
\hline & III/IV & $1 / 2$ & Other types & HGSC & Low & High & \\
\hline \multirow[t]{2}{*}{ ABCA2 } & & $1.46 \pm 0.05^{\mathrm{a}} \quad 1.49 \pm 0.07^{\mathrm{a}}$ & & & & & \\
\hline & NS & $\mathbf{0 . 0 3 8}^{\mathrm{b}}$ & $\mathrm{N}$ & & & & NS \\
\hline \multirow[t]{2}{*}{$\mathrm{ABCA} 3$} & $1.54 \pm 0.07^{\mathrm{a}} \quad 1.47 \pm 0.07^{\mathrm{a}}$ & & & & & & \\
\hline & $0.018^{\mathrm{b}}$ & NS & $\mathrm{N}$ & & & & NS \\
\hline \multirow[t]{2}{*}{$\mathrm{ABCA} 8$} & & & & & & & $\mathrm{r}=0.57$ \\
\hline & NS & NS & $\mathrm{N}$ & & & & $0.007^{\mathrm{c}}$ \\
\hline \multirow[t]{2}{*}{ ABCA9 } & & & & & & & $\mathrm{r}=0.44$ \\
\hline & NS & NS & $\mathrm{N}$ & & & & $0.044^{\mathrm{c}}$ \\
\hline \multirow[t]{2}{*}{ ABCA10 } & & & & & $1.67 \pm 0.16^{\mathrm{a}}$ & $1.85 \pm 0.19^{\mathrm{a}}$ & \\
\hline & NS & NS & $\mathrm{N}$ & & 0.0 & & NS \\
\hline \multirow[t]{2}{*}{ ABCA12 } & $1.80 \pm 0.21^{\mathrm{a}} \quad 2.00 \pm 0.15^{\mathrm{a}}$ & & $1.81 \pm 0.21^{\mathrm{a}}$ & $1.96 \pm 0.16^{\mathrm{a}}$ & & & \\
\hline & $0.045^{\mathrm{b}}$ & NS & 0.0 & & $\mathrm{~N}$ & & NS \\
\hline \multirow[t]{2}{*}{$\mathrm{ABCB} 1$} & & & & & $1.60 \pm 0.14^{\mathrm{a}}$ & $1.74 \pm 0.10^{\mathrm{a}}$ & $\mathrm{r}=0.59$ \\
\hline & NS & NS & $\mathrm{N}$ & & 0.0 & & $0.005^{\mathrm{c}}$ \\
\hline \multirow[t]{2}{*}{$\mathrm{ABCC} 3$} & & & $1.41 \pm 0.14^{\mathrm{a}}$ & $1.54 \pm 0.10^{\mathrm{a}}$ & $1.35 \pm 0.10^{\mathrm{a}}$ & $1.54 \pm 0.16^{\mathrm{a}}$ & $\mathrm{r}=0.56$ \\
\hline & NS & NS & 0.0 & & & & $0.009^{\mathrm{c}}$ \\
\hline \multirow[t]{2}{*}{ ABCC6 } & & & $1.63 \pm 0.13^{\mathrm{a}}$ & $1.74 \pm 0.11^{\mathrm{a}}$ & & & \\
\hline & NS & NS & 0.0 & & & & NS \\
\hline \multirow[t]{2}{*}{$\mathrm{ABCD} 2$} & & & & & $1.58 \pm 0.18^{\mathrm{a}}$ & $1.75 \pm 0.12^{\mathrm{a}}$ & $\mathrm{r}=0.55$ \\
\hline & NS & NS & $\mathrm{N}$ & & & & $0.010^{\mathrm{c}}$ \\
\hline \multirow[t]{2}{*}{$\mathrm{ABCD} 3$} & & & $1.33 \pm 0.04^{\mathrm{a}}$ & $1.38 \pm 0.05^{\mathrm{a}}$ & & & \\
\hline & NS & NS & 0.0 & & $\mathrm{~N}$ & & NS \\
\hline \multirow[t]{2}{*}{ ABCG1 } & & & $1.37 \pm 0.06^{\mathrm{a}}$ & $1.43 \pm 0.08^{\mathrm{a}}$ & $1.35 \pm 0.05^{\mathrm{a}}$ & $1.45 \pm 0.07^{\mathrm{a}}$ & $\mathrm{r}=0.44$ \\
\hline & NS & NS & 0.0 & & & & $0.047^{\mathrm{c}}$ \\
\hline \multirow[t]{2}{*}{ ABCG2 } & & & & & $1.46 \pm 0.09^{\mathrm{a}}$ & $1.60 \pm 0.09^{\mathrm{a}}$ & \\
\hline & NS & NS & $\mathrm{N}$ & & & & NS \\
\hline \multirow[t]{2}{*}{ ATP7A } & $1.50 \pm 0.06^{\mathrm{a}} \quad 1.46 \pm 0.06^{\mathrm{a}}$ & & & & & & \\
\hline & $0.047^{\mathrm{b}}$ & NS & $\mathrm{N}$ & & $\mathrm{N}$ & & NS \\
\hline \multirow[t]{2}{*}{ ATP7B } & $1.42 \pm 0.06^{\mathrm{a}} \quad 1.36 \pm 0.08^{\mathrm{a}}$ & & & & & & \\
\hline & $0.034^{\mathrm{b}}$ & NS & $\mathrm{N}$ & & & & NS \\
\hline \multirow[t]{2}{*}{ SLC16A14 } & & & & & $1.46 \pm 0.09^{\mathrm{a}}$ & $1.59 \pm 0.09^{\mathrm{a}}$ & \\
\hline & NS & NS & $\mathrm{N}$ & & 0.0 & & NS \\
\hline \multirow[t]{2}{*}{ SLC22A5 } & & & $1.47 \pm 0.06^{\mathrm{a}}$ & $1.53 \pm 0.07^{\mathrm{a}}$ & & & \\
\hline & NS & NS & 0.0 & & & & NS \\
\hline
\end{tabular}

B, Validation set

\begin{tabular}{|c|c|c|c|}
\hline \multirow[b]{2}{*}{ Gene } & \multicolumn{2}{|c|}{ Grade } & \multirow[b]{2}{*}{$\mathrm{Ki} 67$ in percentage } \\
\hline & $1 / 2$ & 3 & \\
\hline \multirow[t]{2}{*}{ ABCA2 } & $1.27 \pm 0.05^{\mathrm{a}}$ & $1.31 \pm 0.04^{\mathrm{a}}$ & $\mathrm{r}=0.319$ \\
\hline & & & $0.017^{\mathrm{c}}$ \\
\hline \multirow[t]{2}{*}{ ABCA10 } & & & $\mathrm{r}=0.296$ \\
\hline & & & $0.025^{\mathrm{c}}$ \\
\hline
\end{tabular}


Table IV. Continued.

Associations of transcript levels with all clinicopathological data were analyzed but to retain a concise style only significant results are reported.

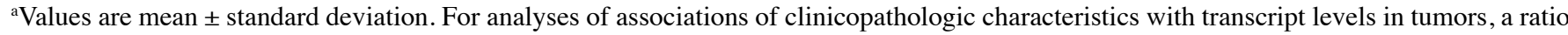
of $\mathrm{Ct}$ for particular target gene to arithmetic mean of $\mathrm{Ct}$ for all reference genes (target gene/REF) was calculated for each sample. Therefore, the lower the target gene/REF ratio the higher is the respective target gene transcript level. ${ }^{\mathrm{b} P}$-values by Kruskal-Wallis test; ${ }^{\mathrm{C}} \mathrm{P}-\mathrm{values}$ by Spearman correlation; r, Spearman's correlation coefficient; ${ }^{\mathrm{d} K i 67}$ protein expression level and progression data are available only for samples from University Hospital in Motol, Prague. Replicated results in both sets are highlighted in bold text. EOC, epithelial ovarian cancer; NS, not significant.
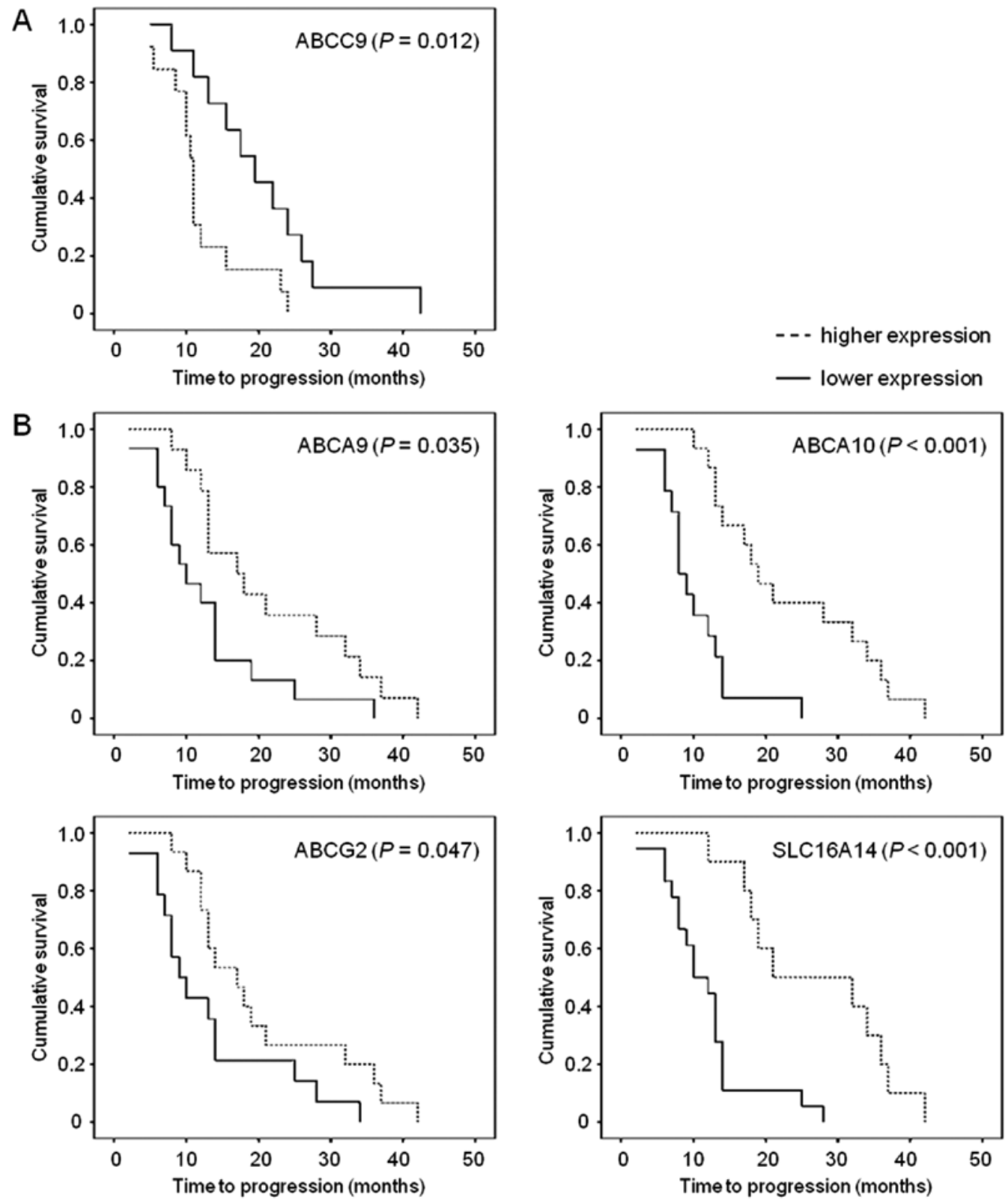

Figure 3. Associations between expression level and time to progression of EOC patients in the pilot (A) and validation (B) set determined by KaplanMeier test.

validation set revealed significant correlation of ABCA2 and ABCA10 levels with expression of marker Ki67.

The association of ABCC9 with PFS of EOC patients observed in the pilot set was not confirmed by the analysis of the validation set $(n=29)$. However, analyses of the validation set discovered significant associations of overexpression of ABCA9 (HR=0.46; 95\% CI, 0.20-1.04), ABCA10 (HR=0.17; 95\% CI, 0.06-0.49), ABCG2 (HR=0.41; 95\% CI, 0.18-0.95), and SLC16A14 $(\mathrm{HR}=0.24 ; 95 \% \mathrm{CI}, 0.09-0.61)$ with longer TTP of EOC patients (Fig. 3B). Multiparametric analysis 
adjusted to stage, grade and presence of distant metastases was significant for ABCA10 ( $\mathrm{P}=0.001)$, ABCG2 $(\mathrm{P}=0.038)$, and SLC16A14 $(\mathrm{P}=0.003)$, but not for ABCA9 $(\mathrm{P}=0.060)$.

Analysis of pooled sets $(\mathrm{n}=53)$ has shown significant result for $\mathrm{ABCG} 2(\mathrm{P}=0.004 ; \mathrm{HR}=0.46 ; 95 \% \mathrm{CI}, 0.25-0.85)$, but not for ABCA9 $(\mathrm{P}=0.335)$, ABCA10 ( $\mathrm{P}=0.080)$, ABCC9 $(\mathrm{P}=0.562)$ or SLC16A14 $(\mathrm{P}=0.125)$. Multiparametric analysis adjusted to stage, grade and presence of distant metastases remained significant for ABCG2 $(\mathrm{P}=0.013)$.

\section{Discussion}

Although various previously reported studies observed significant associations of particular membrane transporters with ovarian carcinoma prognosis and therapy outcome prediction, comprehensive study on the clinicopathologic impact of membrane transporters in ovarian carcinoma is lacking. The present study aimed to partially fill this gap and eventually provide new knowledge and putative markers with prognostic significance or targets for design of novel therapies in EOC.

Several alterations of gene expression levels of $\mathrm{ABC}$ and SLC transporters and ATPases between tumors and controls were found in the present study. Downregulation of ABCA8, ABCA9 and ABCA10 in tumors compared to non-malignant tissues is in line with our previous observation in colorectal carcinomas (7). In addition, ABCB1 gene was downregulated in tumors compared to controls, which corroborates our previous observations in EOC tissues (13), breast (26) and colorectal carcinomas (7). ABCB2, ABCB3 and ABCC3 genes were upregulated in tumors compared to control tissues, which was previously demonstrated in recurrent ovarian carcinomas [but not in primary lesions; (12)] and in pancreatic carcinoma (8). We also observed upregulation of $\mathrm{ABCC} 1$; however, it was not significant $(\mathrm{P}>0.05)$. Thus we could not confirm upregulation of ABCC1 gene previously observed in ovarian carcinomas by Auner et al (12) and by Ehrlichová et al (13).

SLC transporters and ATPases are known to serve as uptake and efflux pumps of platinum-based drugs, respectively, and they also contribute to the resistance of ovarian cancer cells to cisplatin and carboplatin (18-20,27). The observed downregulation (in both pilot and validation sets) of SLC16A14 is in line with its previously reported downregulation in multiresistant W1 ovarian cancer cell line (17). Thus, the validated downregulation of SLC16A14, SLC22A5 and ATP7A in EOC compared to controls observed by the present study implies its potential for prediction of therapy outcome.

The observed downregulation of ABCA2 transcript level in grade 3 tumors compared with grade 1 or 2 carcinomas, which was confirmed in the validation study, raises further interest. Moreover, a negative relationship between ABCA2 expression and expression of protein $\mathrm{Ki} 67$ was revealed in the validation set. Protein marker Ki67 is expressed in highly proliferating cells and linked with advanced stage and high grade ovarian tumors (28). Thus, low ABCA2 expression may be a novel marker of aggressive tumor behavior and its relation to Ki67 should be further investigated.

Besides $\mathrm{ABCA} 2$, other eight $\mathrm{ABC}$ transporter genes (ABCA8/9/10, ABCB1, ABCC3, ABCD2 and ABCG1/2), SLC16A14 and SLC22A5 correlated with Ki67 expression in the pilot study. None of these associations was confirmed in the validation set, however, a negative correlation of ABCA10 with Ki67 level was found, thus implicating a more universal role of this family of ABC transporters. Transporters of ABCA transporters are active in cellular transmembrane lipid transport $(29,30)$ suggesting involvement of lipid transport alterations (caused by decreased expression of particular ABCA genes, e.g. ABCA2 and ABCA10 observed in the pilot study) in increased proliferation of ovarian cancer cells. No further data on associations of ABC and SLC transporter genes with Ki67 marker is available in the literature regarding ovarian cancer. However, higher proportion of Ki67-positive cells in samples of ovarian carcinoma originating from first-look laparotomies was detected in patients with a shorter progression-free time (10). The results of the present study therefore suggest that determination of relationship between mRNA or protein expression of membrane transporters and Ki67 may be important for diagnosis of advanced stages and prognosis of ovarian carcinoma.

Tumors of the ovary are classified into several histological types with HGSC being the most frequent one. The particular types differ in their genetic profiles (31); however, alterations in membrane transporters gene expression are unexplored. In the present study, we identified significant relationships between five ABC (ABCA12, ABCC3, ABCC6, ABCD3 and ABCG1) and SLC22A5 genes, and HGSC which should be further followed. ABCC3 gene confers drug resistance and it is involved in glutathione transport in ovarian cancer cells (32). Recently, ABCC3 was found to serve as a marker for MDR and as a predictor for poor clinical outcome in non-small cell lung cancer (33) which supports our data on ABCC3 overexpression in HGSC tissues. In the study by $\mathrm{Xu}$ et al upregulation of ABCC7 protein was found in serous and clear cell type of ovarian cancer compared to other histological types. It was also connected with proliferation rate of ovarian cancer cells in in vitro experiments, suggesting a potential application of this gene as a marker of EOC aggressiveness (34). In our study, very low level of ABCC7 transcript was detected, thus preventing further study of this gene. However, according to the results of $\mathrm{Xu}$ et al (34), the mechanism of function of $\mathrm{ABCC} 7$ gene in EOC should be followed by functional in vitro experiments.

Gene expression level of ABCC9 was associated with progression-free survival (evaluated as TTP) of EOC patients that were included in the pilot but not in the validation set. Previous study found connection between amplification of ABCC9 and drug resistance in SKOV3/VP ovarian cancer cell line in vitro (35), but $\mathrm{ABCC} 9$ role in prognosis of ovarian carcinoma was unknown. On the contrary, ABCA9, ABCA10, ABCG2 and SLC16A14 significantly associated with PFS in the validation set, but not in the pilot set of patients. The histological subtype variability of analyzed patient sets could be the likely source of these discrepancies. Therefore, we also performed pooled analysis of PFS in both sets together. Only the association of ABCG2 expression with PFS was significant in the combined analysis of both sets and thus ABCG2 appears to be the strongest putative candidate for prognostic marker in EOC patients arising from the present study.

Among the recently studied $\mathrm{ABC}$ transporter genes only members of ABCA subfamily were found to associate with survival of patients. Overexpression of ABCA1/5/8 and 
ABCA9 in primary tumors was significantly associated with the reduced overall survival of ovarian HGSC patients (16). ABCG2 overexpression was recently related to the chemoresistance in ovarian cancer cells $(18,36)$ and so was SLC16A14 overexpression (18). Thus, the role of these genes in chemotherapy response and disease outcome should be further followed in context with other molecular features, e.g. grade or Ki67.

In conclusion, the present study revealed significant differences in gene expression profile of ABC, SLC and ATPase transporters in primary ovarian carcinomas compared with controls, as well as remarkable associations between gene expression and clinicopathologic data of patients. Most notably, expression of ABCA2 gene associated with EOC grade and expression of protein marker Ki67. Moreover, differences in membrane transporters expression profile between HGSC and other histological EOC subtypes were found suggesting the role of particular transporter genes in clinical outcome. ABCA9, ABCA10, ABCC9, ABCG2 and SLC16A14 significantly associated with PFS in one set of the followed patients and ABCG2 in both sets pooled. These genes are thus novel putative markers of ovarian carcinoma prognosis and targets for validation of their clinical utility by a larger independent follow-up study.

\section{Acknowledgements}

The present study was supported by a grant from the Internal Grant Agency of the Czech Ministry of Health no. NT14056-3 to R.V., L.R. and P.V., MH CZ-DRO (National Institute of Public Health-NIPH, 75010330) to M.E., a grant from the Ministry of Education, Youth and Sports of the Czech Republic no. LD14050 to P.V., and the National Sustainability Program I (NPU I) no. LO1503 provided by the Ministry of Education Youth and Sports of the Czech Republic to K.E., M.E. and P.S.

\section{References}

1. Ferlay J, Shin HR, Bray F, Forman D, Mathers C and Parkin DM: Estimates of worldwide burden of cancer in 2008: GLOBOCAN 2008. Int J Cancer 127: 2893-2917, 2010.

2. Hannibal CG, Cortes R, Engholm G and Kjaer SK: Survival of ovarian cancer patients in Denmark: Excess mortality risk analysis of five-year relative survival in the period 1978-2002. Acta Obstet Gynecol Scand 87: 1353-1360, 2008.

3. Bast RC Jr, Hennessy B and Mills GB: The biology of ovarian cancer: New opportunities for translation. Nat Rev Cancer 9: 415-428, 2009.

4. Muggia F: Platinum compounds 30 years after the introduction of cisplatin: Implications for the treatment of ovarian cancer. Gynecol Oncol 112: 275-281, 2009.

5. Bartouskova M, Melichar B and Mohelnikova-Duchonova B: Folate receptor: A potential target in ovarian cancer. Pteridines 26: 1-12, 2015.

6. Kunická T, Václavíková R, Hlaváč V, Vrána D, Pecha V, Rauš K, Trnková M, Kubáčková K, Ambruš M, Vodičková L, et al: Non-coding polymorphisms in nucleotide binding domain 1 in $A B C C 1$ gene associate with transcript level and survival of patients with breast cancer. PLoS One 9: e101740, 2014.

7. Hlavata I, Mohelnikova-Duchonova B, Vaclavikova R, Liska V, Pitule P, Novak P, Bruha J, Vycital O, Holubec L, Treska V, et al: The role of $\mathrm{ABC}$ transporters in progression and clinical outcome of colorectal cancer. Mutagenesis 27: 187-196, 2012.

8. Mohelnikova-Duchonova B, Brynychova V, Oliverius M, Honsova E, Kala Z, Muckova K and Soucek P: Differences in transcript levels of ABC transporters between pancreatic adenocarcinoma and nonneoplastic tissues. Pancreas 42: 707-716, 2013.
9. Eyre R, Harvey I, Stemke-Hale K, Lennard TW, Tyson-Capper A and Meeson AP: Reversing paclitaxel resistance in ovarian cancer cells via inhibition of the ABCB1 expressing side population. Tumour Biol 35: 9879-9892, 2014.

10. Surowiak P, Materna V, Kaplenko I, Spaczynski M, Dietel M, Lage $\mathrm{H}$ and Zabel M: Topoisomerase 1A, HER/2neu and Ki67 expression in paired primary and relapse ovarian cancer tissue samples. Histol Histopathol 21: 713-720, 2006.

11. Bram EE, Stark M, Raz S and Assaraf YG: Chemotherapeutic drug-induced ABCG2 promoter demethylation as a novel mechanism of acquired multidrug resistance. Neoplasia 11: 1359-1370, 2009.

12. Auner V, Sehouli J, Oskay-Oezcelik G, Horvat R, Speiser P and Zeillinger R: $\mathrm{ABC}$ transporter gene expression in benign and malignant ovarian tissue. Gynecol Oncol 117: 198-201, 2010.

13. Ehrlichová M, Mohelnikova-Duchonova B,Hrdy J, Brynychova V, Mrhalova M, Kodet R, Rob L, Pluta M, Gut I, Soucek P, et al: The association of taxane resistance genes with the clinical course of ovarian carcinoma. Genomics 102: 96-101, 2013.

14. Lu L, Katsaros D, Wiley A, Rigault de la Longrais IA, Puopolo M and $\mathrm{Yu} \mathrm{H}$ : Expression of $M D R 1$ in epithelial ovarian cancer and its association with disease progression. Oncol Res 16: 395-403, 2007.

15. Bagnoli M, Beretta GL, Gatti L, Pilotti S, Alberti P, Tarantino E, Barbareschi M, Canevari S, Mezzanzanica D and Perego P: Clinicopathological impact of $\mathrm{ABCC} 1 / \mathrm{MRP} 1$ and $\mathrm{ABCC} 4 /$ MRP4 in epithelial ovarian carcinoma. Biomed Res Int 2013: 143202, 2013

16. Hedditch EL, Gao B, Russell AJ, Lu Y, Emmanuel C, Beesley J, Johnatty SE, Chen X, Harnett P, George J, et al; Australian Ovarian Cancer Study Group: $A B C A$ transporter gene expression and poor outcome in epithelial ovarian cancer. J Natl Cancer Inst 106: dju149, 2014.

17. Januchowski R, Zawierucha P, Andrzejewska M, Ruciński M and Zabel M: Microarray-based detection and expression analysis of $\mathrm{ABC}$ and SLC transporters in drug-resistant ovarian cancer cell lines. Biomed Pharmacother 67: 240-245, 2013.

18. Januchowski R, Zawierucha P, Ruciński M, Andrzejewska M, Wojtowicz K, Nowicki M and Zabel M: Drug transporter expression profiling in chemoresistant variants of the A2780 ovarian cancer cell line. Biomed Pharmacother 68: 447-453, 2014.

19. Katano K, Safaei R, Samimi G, Holzer A, Rochdi M and Howell SB: The copper export pump ATP7B modulates the cellular pharmacology of carboplatin in ovarian carcinoma cells. Mol Pharmacol 64: 466-473, 2003.

20. Samimi G, Safaei R, Katano K, Holzer AK, Rochdi M, Tomioka M, Goodman M and Howell SB: Increased expression of the copper efflux transporter ATP7A mediates resistance to cisplatin, carboplatin, and oxaliplatin in ovarian cancer cells. Clin Cancer Res 10: 4661-4669, 2004.

21. Moreno-Smith M, Halder JB, Meltzer PS, Gonda TA, Mangala LS, Rupaimoole R, Lu C, Nagaraja AS, Gharpure KM, Kang Y, et al: ATP11B mediates platinum resistance in ovarian cancer. J Clin Invest 123: 2119-2130, 2013.

22. Hubackova M, Vaclavikova R, Ehrlichova M, Mrhalova M, Kodet R, Kubackova K, Vrána D, Gut I and Soucek P: Association of superoxide dismutases and $\mathrm{NAD}(\mathrm{P}) \mathrm{H}$ quinone oxidoreductases with prognosis of patients with breast carcinomas. Int $\mathrm{J}$ Cancer 130: 338-348, 2012.

23. Soucek P, Anzenbacher P, Skoumalová I and Dvorák M: Expression of cytochrome P450 genes in $\mathrm{CD} 34^{+}$hematopoietic stem and progenitor cells. Stem Cells 23: 1417-1422, 2005.

24. Mohelnikova-Duchonova B, Oliverius M, Honsova E and Soucek P: Evaluation of reference genes and normalization strategy for quantitative real-time PCR in human pancreatic carcinoma. Dis Markers 32: 203-210, 2012.

25. Bustin SA, Benes V, Garson JA, Hellemans J, Huggett J, Kubista M, Mueller R, Nolan T, Pfaffl MW, Shipley GL, et al: The MIQE guidelines: Minimum information for publication of quantitative real-time PCR experiments. Clin Chem 55: 611-622, 2009.

26. Hlaváč V, Brynychová V, Václavíková R, Ehrlichová M, Vrána D, Pecha V, Koževnikovová R, Trnková M, Gatěk J, Kopperová D, et al: The expression profile of ATP-binding cassette transporter genes in breast carcinoma. Pharmacogenomics 14: 515-529, 2013.

27. Burger H, Zoumaro-Djayoon A, Boersma AW, Helleman J, Berns EM, Mathijssen RH,Loos WJ and Wiemer EA: Differential transport of platinum compounds by the human organic cation transporter hOCT2 (hSLC22A2). Br J Pharmacol 159: 898-908, 2010. 
28. Kamal CK, Simionescu CE, Mărgăritescu C and Stepan A: P53 and Ki67 immunoexpression in mucinous malignant ovarian tumors. Rom J Morphol Embryol 53 (Suppl 3): S799-S803, 2012.

29. Kaminski WE, Orsó E, Diederich W, Klucken J, Drobnik W and Schmitz G: Identification of a novel human sterol-sensitive ATP-binding cassette transporter (ABCA7). Biochem Biophys Res Commun 273: 532-538, 2000.

30. Jessup W, Gelissen IC, Gaus K and Kritharides L: Roles of ATP binding cassette transporters A1 and G1, scavenger receptor BI and membrane lipid domains in cholesterol export from macrophages. Curr Opin Lipidol 17: 247-257, 2006.

31. Beaufort CM, Helmijr JC, Piskorz AM, Hoogstraat M, RuigrokRitstier K, Besselink N, Murtaza M, van IJcken WF, Heine AA Smid M, et al: Ovarian cancer cell line panel (OCCP): Clinical importance of in vitro morphological subtypes. PLoS One 9: e103988, 2014

32. Kool M, van der Linden M, de Haas M, Scheffer GL, de Vree JM, Smith AJ, Jansen G, Peters GJ, Ponne N, Scheper RJ, et al: MRP3, an organic anion transporter able to transport anti-cancer drugs. Proc Natl Acad Sci USA 96: 6914-6919, 1999.
33. Zhao Y, Lu H, Yan A, Yang Y, Meng Q, Sun L, Pang H, Li C, Dong X and Cai L: ABCC3 as a marker for multidrug resistance in non-small cell lung cancer. Sci Rep 3: 3120, 2013.

34. Xu J, Yong M, Li J, Dong X, Yu T, Fu X and Hu L: High level of CFTR expression is associated with tumor aggression and knockdown of CFTR suppresses proliferation of ovarian cancer in vitro and in vivo. Oncol Rep 33: 2227-2234, 2015.

35. Yasui K, Mihara S,Zhao C, Okamoto H, Saito-Ohara F, Tomida A, Funato T, Yokomizo A, Naito S, Imoto I, et al: Alteration in copy numbers of genes as a mechanism for acquired drug resistance. Cancer Res 64: 1403-1410, 2004.

36. He QZ, Luo XZ, Wang K, Zhou Q, Ao H, Yang Y, Li SX, Li Y, Zhu HT and Duan T: Isolation and characterization of cancer stem cells from high-grade serous ovarian carcinomas. Cell Physiol Biochem 33: 173-184, 2014. 